\title{
PERANGKAIAN GERBANG LOGIKA DENGAN MENGGUNAKAN MATLAB (SIMULINK)
}

\author{
${ }^{1}$ Ikhsan Parinduri, ${ }^{2}$ Siti Nurhabibah Hutagalung \\ ${ }^{1}$ STMIK Royal Kisaran, ${ }^{2}$ STMIK Budi Darma \\ email: ${ }^{1}$ ikhsanparinduri9@gmail.com ${ }^{2}$ Siti_nurhabibah69@yahoo.com
}

\begin{abstract}
Abstrack: The logic gate circuit using the simulink method matlab is a series of ways to prove between theories in simulation using the matlab program by entering parameters in the truth table at each logic gate. Parameters in the truth table consist of logic 0 for low and logic 1 for high. The simulation is done by giving input (input) and outpout (output) at each basic logic gate which consists of 7 gates of which are NOT gates, AND, OR, NAND, NOR, X-OR and X-NOR. This proof is intended as a medium to study the logic gate in higher learning learning in digital engineering learning and digital systems.
\end{abstract}

\section{Keywords: Logic Gate, Matlab, Simulink}

Abstrak: Perangkaian gerbang logika dengan menggunakan matlab metode simulink adalah perangkaian dengan cara pembuktian antara teori pada simulasi menggunakan program matlab dengan memasukkan parameter-paramater yang ada pada tabel kebenaran pada setiap gerbang logika. Paramter-paramater pada tabel kebenaran terdiri atas logika 0 untuk low dan logika 1 untuk high. Simulasi dilakukan dengan memberikan input (masukan) dan outpout (keluaran) pada setiap gerbang logika dasar yang teriri dari 7 gerbang daiantaranya adalah gerbang NOT, AND, OR, NAND, NOR, X-OR dan XNOR. Pembuktian ini bertujuan sebagai media untuk mempelajari gerbang logika pada pembelajaran diperguruan tinggi pada pembelajaran teknik digital maupun sistem digital.

\section{Kata kunci : Gerbang Logika, Matlab, Simulink}

\section{PENDAHULUAN}

Pada jaman sekarang ini, teknologi berkembang sangat pesat. Bermacam - macam alat yang sudah dihasilkan. Sekarang, hampir semua peralatan yang bekerja dengan tegangan listrik sudah menggunakan rangkaian digital. Saat ini rangkaian elektronika digital sudah bukan barang asing lagi.

Rangkaian digital sudah ada di mana-mana dan bersinergi dengan rangkaian elektronika analog untuk membentuk rangkaian - rangkaian elektronika yang lebih cermat, cepat, dan tepat sasaran Sebenarnya, sebuah rangkaian digital tidak harus selalu berupa rangkaian rumit dengan banyak komponen kecil seperti yang kita lihat di dalam komputer, handphone, ataupun kalkulator. Sebuah rangkaian dengan kerja sederhana yang menerapkan prinsip-prinsip digital, juga merupakan sebuah rangkaian digital.

Gerbang Logika atau dalam bahasa Inggris disebut dengan Logic Gate adalah dasar pembentuk Sistem Elektronika Digital yang berfungsi untuk mengubah satu atau beberapa Input (masukan) menjadi sebuah 
sinyal Output (Keluaran) Logis.

Gerbang Logika beroperasi berdasarkan sistem bilangan biner yaitu bilangan yang hanya memiliki 2 kode simbol yakni 0 dan 1 dengan menggunakan Teori Aljabar Boolean. Gerbang Logika yang diterapkan dalam Sistem Elektronika Digital pada dasarnya menggunakan komponen-kompenen Elektronika seperti Integrated Circuit (IC), Dioda, Transistor, Relay, Optik maupun Elemen Mekanikal.

Gerbang yang diterjemahkan dari istilah asing gate, adalah elemen dasar dari semua rangkaian yang menggunakan sistem digital. Semua fungsi digital pada dasarnya tersusun atas gabungan beberapa gerbang logika dasar yang disusun berdasarkan fungsi yang diinginkan. Gerbang -gerbang dasar ini bekerja atas dasar logika tegangan yang digunakan dalam teknik digital.Logika tegangan adalah asas dasar bagi gerbang-gerbang logika. Dalam teknik digital apa yang dinamakan logika tegangan adalah dua kondisi tegangan yang saling berlawanan.

Kondisi tegangan "ada tegangan" mempunyai istilah lain "berlogika satu" (1) atau "berlogika tinggi" (high), sedangkan "tidak ada tegangan" memiliki istilah lain "berlogika nol" (0) atau "berlogika rendah" (low). Dalam membuat rangkaian logika kita menggunakan gerbang-gerbang logika yang sesuai dengan yang dibutuhkan. Rangkaian digital adalah sistem yang mempresentasikan sinyal sebagai nilai diskrit. Dalam sebuah sirkuit digital,sinyal direpresentasikan dengan satu dari dua macam kondisi yaitu 1 (high, active, true,) dan 0 (low, nonactive,false), (Sendra, Et.al, 1989).

Matlab adalah sebuah bahasa dengan kinerja tinggi untuk komputasi masalah teknik. Matlab mengintegrasikan komputasi, visualisasi, dan pemrograman dalam suatu model yang sangat mudah untuk pakai dimana masalahmasalah dan penyelesaiannya diekspresikan dalam notasi matematika yang familiar.

Dalam lingkungan perguruan tinggi teknik, Matlab merupakan perangkat standar untuk memperkenalkan dan mengembangkan penyajian materi matematika, rekayasa dan kelimuan. Di industri, Matlab merupakan perangkat pilihan untuk penelitian dengan produktifitas yang tingi, pengembangan dan analisanya. Fiturfitur Matlab sudah banyak dikembangkan, dan lebih kita kenal dengan nama toolbox.

Sangat penting bagi seorang pengguna Matlab, toolbox mana yang mandukung untuk learn dan apply technology yang sedang dipelajarinya. Toolbox ini merupakankumpulan dari fungsifungsi Matlab (M-files) yang telah dikembangkan ke suatu lingkungan kerja Matlab untuk memecahkan masalah dalam kelas particular.

Area-area yang sudah bisa dipecahkan dengan toolbox saat ini meliputi pengolahan sinyal, system kontrol, neural networks, fuzzy logic, wavelets, dan lain-lain.

Perangkaian Gerbang logika menggunakan Matlab (Simulink) dimaksudkan untuk mensimulasikan rangkaian gerbang logika dan membuktikan antara teori tentang gerbang logika ke dalam bentuk 
JURTEKSI (Jurnal Teknologi dan Sistem Informasi)

Vol. V No. 1, Des 2018, hlm. 63 - 70

DOI: https://doi.org/10.33330/jurteksi.v5i1.300

Available online at http://jurnal.stmikroyal.ac.id/index.php/jurteksi
ISSN 2407-1811 (Print)

ISSN 2550-0201 (Online) program atau software secara komputerisasi.

\section{Gerbang Logika}

Gerbang logika atau gerbang logik adalah suatu entitas dalam elektronika dan matematika boolean yang mengubah satu atau beberapa masukan logik menjadi sebuah sinyal keluaran logik. Gerbang logika terutama diimplementasikan secara elektronis menggunakan dioda atau transistor, akan tetapi dapat pula dibangun menggunakan susunan komponen-komponen yang memanfaatkan sifat-sifat elektromagnetik (relay).

Logika merupakan dasar dari semua penalaran (reasoning). Untuk menyatukan beberapa logika, kita membutuhkan operator logika dan untuk membuktikan kebenaran dari logika, kita dapat menggunakan tabel kebenaran. Tabel kebenaran menampilkan hubungan antara nilai kebenaran dari proposisi atomik. Dengan tabel kebenaran, suatu persamaan logika ataupun proposisi bisa dicari nilai kebenarannya.

Tabel kebenaran pasti mempunyai banyak aplikasi yang dapat diterapkan karena mempunyai fungsi tersebut. Salah satu dari aplikasi tersebut yaitu dengan menggunakan tabel kebenaran kita dapat mendesain suatu rangkaian logika. Dalam makalah ini akan dijelaskan bagaimana peran dan kegunaan tabel kebenaran dalam proses pendesainan suatu rangkaian logika.

\section{Rangkaian Terpadu (IC) Untuk Gerbang - Gerbang Dasar}

Setelah mengenal gerbanggerbang dasar yang digunakan dalam teknik digital, bagi para pemula mengkin saja timbul pertanyaan dimana gerbang-gerbang ini dapat diperoleh? Jawabannya mudah sekali, karena gerbang- gerbang ini telah dijual secara luas dipasaran dalam IC tunggal (single chip). Yang perlu diperhatikan sekarang adalah dari jenis apa dan bagaimana penggunaan dari kaki-kaki IC yang telah didapat.

Sebenarnya informasi dari ICIC yang ada dapat dengan mudah ditemukan dalam buku data sheet IC yang sekarang ini banyak dijual. Namun sedikit contoh berikut mungkin akan me mpermudah pencarian. Berikut adalah keterangan mengenai IC-IC yang mengandung gerbang-gerbang logika dasar yang dengan mudah dapat dijumpai dipasaran.

Ada dua golongan besar IC yang umum digunakan yaitu TTL dan CMOS. IC dari jenis TTL memiliki mutu yang relatif lebih baik daripada CMOS dalam hal daya yang dibutuhkan dan kekebalannya akan desah.

IC TTL membutuhkan catu tegangan sebesar $5 \mathrm{~V}$ sedangkan CMOS dapat diberi catu tegangan mulai $8 \mathrm{~V}$ sampai $15 \mathrm{~V}$. Hali ini harus diingat benar-benar karena kesalahan pemberian catu akan merusakkan IC.

Karena adanya perbedaan tegangan catu maka tingkat tegangan logika juga akan berbeda. Untuk TTL logika satu diwakili oleh tegangan sebesar maksimal $5 \mathrm{~V}$ sedangkan untuk CMOS diwakili oleh tegangan yang maksimalnya sebesar catu yang diberikan, bila catu yang diberikan adalah $15 \mathrm{~V}$ maka logika satu akan diwakili oleh 
tegangan maksimal sebesar $15 \mathrm{~V}$. Logika pada TTL dan CMOS adalah suatu tegangan yang harganya mendekati nol. Untuk TTL nama IC yang biasanya terdiri atas susunan angka dimulai dengan angka 74 atau 54 sedangkan untuk CMOS angka ini diawali dengan 40."(Ian Robertson, et. al 1993).

\section{RANGKAIAN DASAR \\ GERBANG LOGIKA}

\section{Gerbang NOT (NOT Gate)}

Gerbang NOT atau juga bisa disebut dengan pembalik (inverter) memiliki fungsi membalik logika tegangan inputnya pada outputnya. Sebuah inverter (pembalik) adalah gerbang dengan satu sinyal masukan dan satu sinyal keluaran dimana keadaan keluaranya selalu berlawanan dengan keadaan masukan.

Membalik dalam hal ini adalah mengubah menjadi lawannya. Karena dalam logika tegangan hanya ada dua kondisi yaitu tinggi dan rendah atau " 1 " dan "0", maka membalik logika tegangan berarti mengubah "1" menjadi " 0 " atau sebaliknya mengubah nol menjadi satu. Simbul atau tanda gambar pintu NOT ditunjukkan pada gambar dibawah ini.
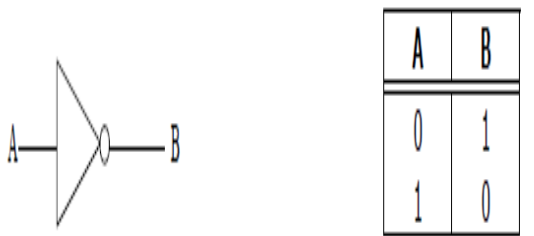

Gambar 1. Simbol dan Tabel Kebenaran Gerbang NOT

\section{Gerbang AND (AND GATE)}

Gerbang AND (AND GATE) atau dapat pula disebut gate AND ,adalah suatu rangkaian logika yang mempunyai beberapa jalan masuk (input) dan hanya mempunyai satu jalan keluar (output) Gerbang AND mempunyai dua atau lebih dari dua.

Dalam gerbang sukan AND, untuk menghasilkan sinyal keluaran tinggi maka semua sinyal masukan harus bernilai tinggi.

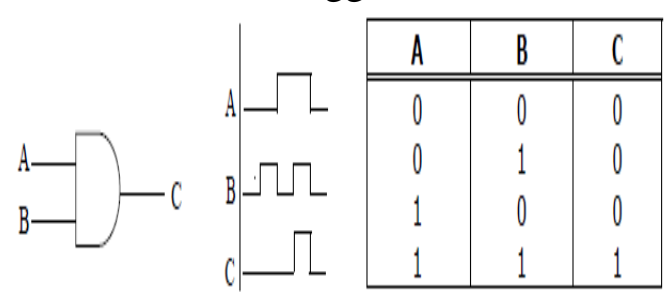

\section{Gambar 2. Simbol dan Tabel Kebenaran Gerbang AND}

\section{Gerbang OR (OR GATE)}

Gerbang OR berbeda dengan gerbang NOT yang hanya memiliki satu input, gerbang ini memiliki paling sedikit 2 jalur input. Artinya inputnya bisa lebih dari dua, misalnya empat atau delapan. Yang jelas adalah semua gerbang logika selalu mempunyai hanya satu output.

Gerbang OR akan memberikan sinyal keluaran tinggi jika salah satu atau semua sinyal masukan bernilai tinggi, sehingga dapat dikatakan bahwa gerbang OR hanya memiliki sinyal keluaran rendah jika semua sinyal masukan bernilai rendah.

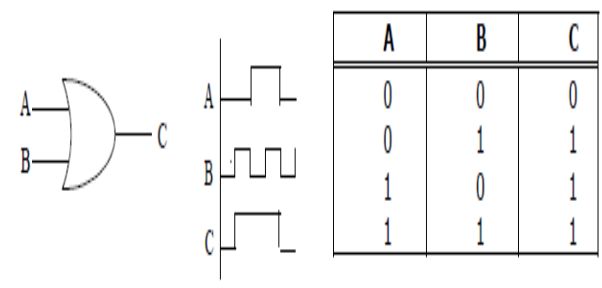

\section{Gambar 3. Simbol dan Tabel Kebenaran Gerbang OR}


DOI: https://doi.org/10.33330/jurteksi.v5i1.300

Available online at http://jurnal.stmikroyal.ac.id/index.php/jurteksi

\section{Gerbang NAND}

Gerbang NAND adalah suatu NOT-AND, atau suatu fungsi AND yang dibalikkan. Dengan kata lain bahwa gerbang NAND akan menghasilkan sinyal keluaran rendah jika semua sinyal masukan bernilai tinggi.

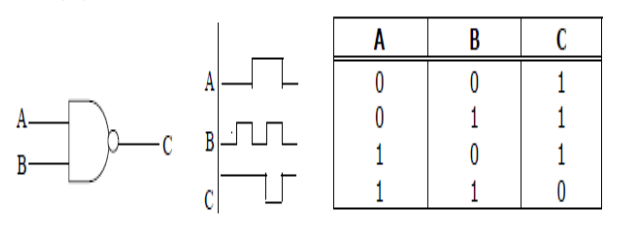

\section{Gambar 4. Simbol dan Tabel} Kebenaran Gerbang NAND

\section{Gerbang NOR}

Gerbang NOR adalah suatu NOT-OR, atau suatu fungsi OR yang dibalikkan sehingga dapat dikatakan bahwa gerbang NOR akan menghasilkan sinyal keluaran tinggi jika semua sinyal masukanya bernilai rendah.

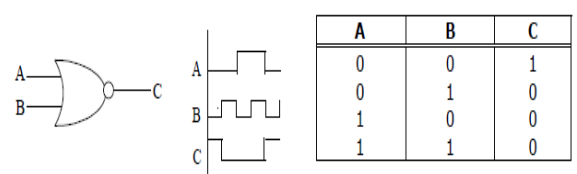

\section{Gambar 5. Simbol dan Tabel Kebenaran Gerbang NOR}

\section{Gerbang X-OR}

Gerbang X-OR akan menghasilkan sinyal keluaran rendah jika semua sinyal masukan bernilai rendah atau semua masukan bernilai tinggi atau dengan kata lain bahwa $\mathrm{X}-\mathrm{OR}$ akan menghasilkan sinyal keluaran rendah jika sinyal masukan bernilai sama semua.

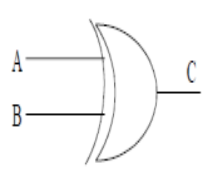

\begin{tabular}{|l|l|l|}
\hline$A$ & $B$ & $C$ \\
\hline 0 & 0 & 0 \\
0 & 1 & 1 \\
1 & 0 & 1 \\
1 & 1 & 0 \\
\hline
\end{tabular}

Gambar 6. Simbol dan Tabel Kebenaran Gerbang X-OR

\section{Gerbang X-NOR}

Gerbang X-NOR akan menghasilkan sinyal keluaran tinggi jika semua sinyal masukan bernilai sama (kebalikan dari gerbang $\mathrm{X}$ OR).

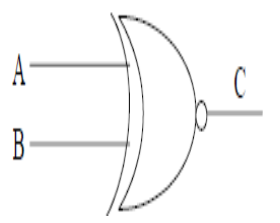

\begin{tabular}{|c|c|c|}
\hline$A$ & $B$ & $C$ \\
\hline \hline 0 & 0 & 1 \\
0 & 1 & 0 \\
1 & 0 & 0 \\
1 & 1 & 1 \\
\hline
\end{tabular}

Gambar 7. Simbol dan Tabel Kebenaran Gerbang X-NOR

\section{MATLAB}

Matlab adalah kependekan dari MATrix Laboratory dikarenakan setiap data pada MATLAB menggunakan dasar matriks. MATLAB adalah bahasa pemrograman tinggi, tertutup dan case sensitive dalam lingkungan komputasi numerik yang dikembangkan oleh MathWorks. Salah satu kelebihannya yang paling populer adalah kemampuan membuat grafik dengan dukungan kustomisasi terbaik.

$$
\text { MATLAB mempunyai }
$$

banyak tools yang dapat membantu berbagai disiplin ilmu. Ini merupakan salah satu penyebab industri menggunakan MATLAB. Selain itu MATLAB mempunyai banyak library yang sangat membantu untuk menyelesaikan permasalahan matematika seperti membuat simulasi fungsi, pemodelan matematika dan perancangan GUI.

\section{Bagian Utama MATLAB}

Sebagai sebuah sistem, MATLAB tersusun dari 5 bagian utama: 
1. Development Environment, merupakan sekumpulan perangkat dan fasilitas yang membantu kita untuk menggunakan fungsi-fungsi dan file-file MATLAB. Beberapa perangkat ini merupakan sebuah Graphical User Interfaces (GUI). Termasuk didalamnya adalah MATLAB desktop dan Command Window, Command History, sebuah editor dan debugger, dan browsers untuk melihat help, workspace, files, dan search path.

\section{MATLAB Mathematical}

Function Library, merupakan sekumpulan algoritma komputasi mulai dari fungsi-fungsi dasar sepertri: sum, sin, cos, dan complex arithmetic, sampai dengan fungsi-fungsi yang lebih kompek seperti matrix inverse, matrix

eigenvalues, Bessel functions, dan fast Fourier transforms.

3. MATLAB Language, merupakan suatu high-level matrix/array language dengan control flow statements, functions, data structures, input/output, dan fiturfitur object-oriented programming. Graphics, MATLAB memiliki fasilitas untuk menampilkan vector dan matrices sebagai suatu grafik.

4. MATLAB Application Program Interface (API), merupakan suatu library yang memungkinkan program yang telah kita tulis dalam bahasa $C$ dan Fortran mampu berinterakasi dengan MATLAB. Ini melibatkan fasilitas untuk pemanggilan routines dari MATLAB (dynamic linking), pemanggilan MATLAB sebagai sebuah computational engine, dan untuk membaca dan menuliskan MAT-files.

\section{METODE}

\section{Analisa Permasalahan}

Permasalahan

dalam

perangkaian gerbang logika menggunakan matlab didapat adalah bagaimana pembuktian antara teori yang ada dengan membuat simulasi gerbang logika dengan software matlab, apakah dpat disimulasikan, memasukkan nilai paramter-paramter input dan ouput pada semua nilai pada tabel kebenaran gerbang logika dengan nilai 1 untuk high dan nilai 0 untuk low.

\section{Metode yang diterapkan}

Metode yang diterapkan adalah dengan metode simulasi menggunakan Matlab (Simulink). Penerapan Metode ini dengn cara melihat parameter-parameter pada gerbang logika dasar yang terdapat pada tabel kebenaran setiap gerbang logika.

\section{ANALISA DAN HASIL}

Pada tampilan Home pilih menu Simulink:

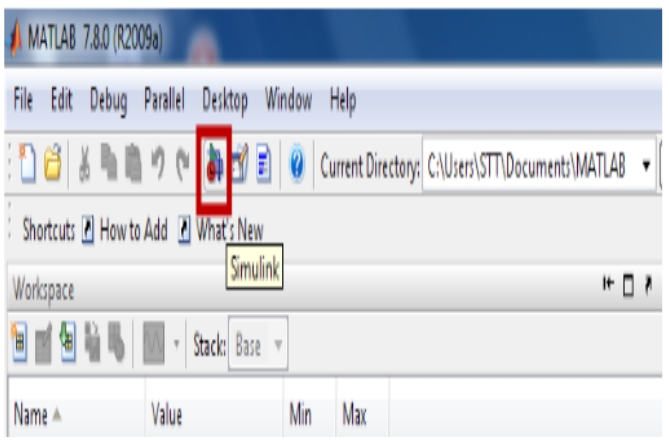

Gambar 8. Tampilan pada Simulink Apabila menu simulink dipilih maka akan muncul Simulink Library Browser, kemudian pilih new model 
JURTEKSI (Jurnal Teknologi dan Sistem Informasi)

Vol. V No. 1, Des 2018, hlm. 63 - 70

DOI: https://doi.org/10.33330/jurteksi.v5i1.300

Available online at http://jurnal.stmikroyal.ac.id/index.php/jurteksi

sehingga akan mucul tampilan window dengan nama untitled.

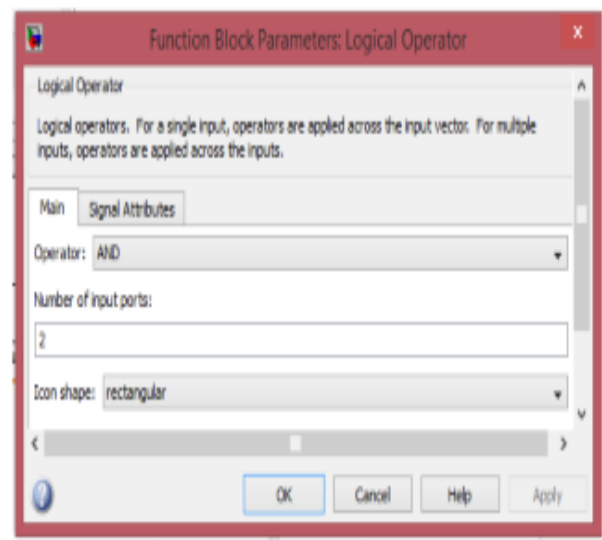

Gambar 9. Simulink Library Browse

Tampilan new window untitled berfungsi sebagai media pembuatan simulasi, dalam pembuatan blok simulasi gerbang logika digunakan beberapa block description, yaitu :

Pilihan Constant (Simulink) Commonly Used Blocks/ Constant)

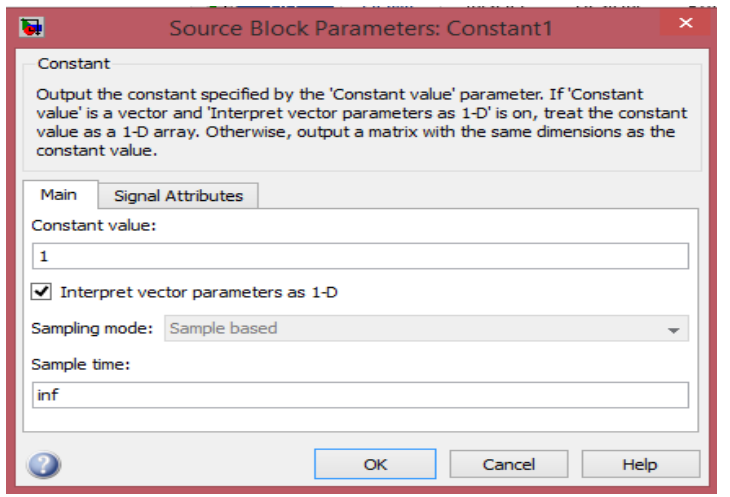

Gambar 10. Pengisian Logika Operator

Logika operatot Constant berfungsi untuk memberi masukan atau input pada gerbang logika melalui constant value yang bernilai 1 atau 0.

Piliihlah simbol untuk Logical Operator (Simulink / Commonly Used Blocks/Logical Operator) untuk logika AND
ISSN 2407-1811 (Print)

ISSN 2550-0201 (Online) 
DOI: https://doi.org/10.33330/jurteksi.v5i1.300

Available online at http://jurnal.stmikroyal.ac.id/index.php/jurteksi

belum tepat pada titik hubungnya).

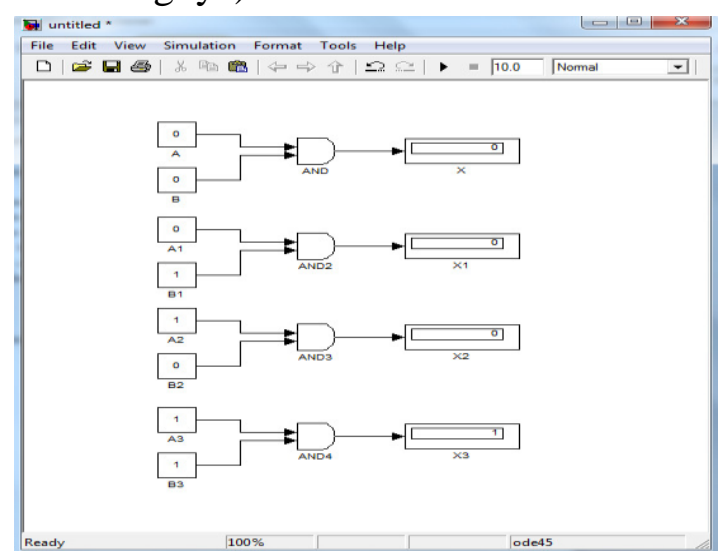

\section{Gambar 12. Perangkaian Gerbang} Logika AND

Kemudian Lakukan perangkaian 3 jenis gerbang logika.



Gambar 13. Block Description 3 jenis gerbang logika

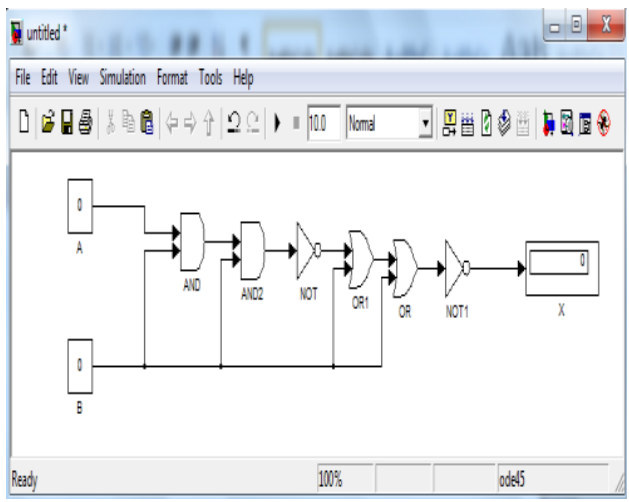

Gambar 14. Perangkaian Gerbang AND, NOT, OR

\section{KESIMPULAN}

Dari hasil penelitian didapat beberap kesipmulan diantaranya adalah:

1. Perangkaian gerbang logika dapat dilakukan dengan program matlab metode simulink cara simulasi

2. Perangkaian gerbang logika dengan simulasi dapat membantu dalam pembuktian teori-teori yang ada dan sebagai media pembelajaran teknik digital.

\section{DAFTAR PUSTAKA}

[1] Agustian I. Panduan Praktikum Elektronika.Lab TE.2008.

[2] Ian Robertson Sinclair, Suryawan," Panduan Belajar Elektronik Digital", Elex Media Komputindo, Jakarta, 1993.

[3] Sendra, Smith, Keneth C.," Rangkaian Mikroelektronika”, Penerbit Erlangga, Jakarta, 1989.

[4] Tokheim ,R.L. Elektronika Digital. Mc Graw Hill. 1998. 